\title{
Patrón Crazy Paving en una mujer joven. Hallazgo inesperado y tratamiento no tradicional en un caso de proteinosis alveolar pulmonar
}

\author{
PATRICIO RIOSECO S.*, SUSANA MUÑOZ V.*, CAMILA VIVALDI B.**, \\ ANDRÉS FUICA DE LA V.** y CARMEN BARI T.***
}

\section{Crazy paving computed tomography pattern in a young woman. Unexpected findings and non-traditional treatment in a pulmonary alveolar proteinosis case}

Crazy paving computed tomography pattern may be due to a number of causes, one of them being Pulmonary Alveolar Proteinosis, a rare condition leading to respiratory failure and often to death. We present the case of a young woman with a one-year history of progressive dyspnea and dry cough, who consulted for an acute onset of fever, chills, malaise and severe hypoxemic respiratory failure $\left(\mathrm{PaO}_{2}=51.9 \mathrm{mmHg} ; \mathrm{FiO}_{2}=0.50\right)$ with a 'crazy paving' pattern on chest CT. This diagnostic challenge was resolved by a surgical lung biopsy that showed a pulmonary alveolar proteinosis.Taking into account that the traditional treatment using whole lung lavage had already failed in this patient, a novel therapeutic approach was settled. A series of 4 lobar lavages with a perfluorocarbon (Perflubron) under local anesthesia followed by 5 plasmapheresis sessions were carried out. The patient showed radiographic and functional improvement almost immediately after this treatment. $\mathrm{PaO}_{2}$ was $89.9 \mathrm{mmHg}$ breathing room air and FVC and FEV $V_{1}$ increased to reach 77 and $75 \%$ respectively of their normal reference values. Because of its chemical and physical properties we think this novel therapeutic approach should be a valuable alternative to saline solution for whole lung lavage in these cases.

Key words: Pulmonar Alveolar Proteinosis;Tomography, XRay Computed; Bronchoalveolar Lavage; Perfluorocarbon; Plasmapheresis; Respiratory Insufficiency.

\section{Resumen}

El patrón llamado 'crazy paving' en tomografía computada de tórax (TAC) puede deberse a diferentes condiciones siendo una de ellas la Proteinosis Alveolar Pulmonar (PAP), rara condición que puede llevar a insuficiencia respiratoria y a menudo, a la muerte. Presentamos el caso de una mujer joven con una historia de un año de evolución de disnea progresiva y tos seca que consultó por un cuadro de aparición brusca de fiebre, calofrios, malestar general y falla respiratoria hipoxémica severa $\left(\mathrm{PaO}_{2}=51,9 \mathrm{mmHg}\right.$ con $\left.\mathrm{FiO}_{2}=0,50\right)$ en la cual la TAC de tórax mostraba un patrón de empedrado $o$ 'crazy paving' que significó un desafio diagnóstico resuelto finalmente con una biopsia pulmonar quirúrgica que mostró una PAP. Ante el fracaso del tratamiento tradicional de Lavado Pulmonar Total (LPT) se usó una aproximación terapéutica novedosa consistente en una serie de 4 lavados lobares con un perfluorocarbono, Perflubron (PFC) bajo anestesia local seguido por 5 sesiones de Plasmaféresis. Casi inmediatamente después de este tratamiento la paciente evidenció mejoría radiológica y funcional. $\mathrm{La} \mathrm{PaO}_{2}$ fue de $89,9 \mathrm{mmHg}$ respirando aire ambiental y la $\mathrm{CVF}$ y el VEF ${ }_{1}$ aumentaron alcanzado respectivamente el 77 y el $75 \%$ de sus valores normales de referencia. Dadas las características químicas y fisicas del PFC, pensamos que es una alternativa válida al LPT en estos casos.

Palabras clave: Proteinosis Alveolar Pulmonar, Lavado broncoalveolar, Tomografía computarizada; Perfluorocarbono, Plasmaféresis; Insuficiencia respiratoria.

\footnotetext{
* Unidad de Enfermedades Respiratorias Hospital Las Higueras. Talcahuano, Chile.

** Becado de la Especialidad de Medicina Interna, Facultad de Medicina Universidad de Concepción. Concepción, Chile.

*** Unidad de Anatomía Patológica, Hospital Las Higueras. Talcahuano, Chile.
} 


\section{Presentación del caso clínico}

Una mujer de 43 años de edad, aseadora de camiones de carga en el puerto de Lirquén fue enviada desde un hospital periférico con la historia de aparición brusca de fiebre elevada, calofríos, malestar general y disnea severa desde hacía ya 7 días. Tenía el antecedente de ser fumadora de 20 paquetes/año y relataba tener disnea progresiva de un año de evolución acompañada de tos seca.

Al examen físico, estaba febril, con temperatura de $38^{\circ} \mathrm{C}$, polipneica, cianosis periférica e hipocratismo digital. El examen torácico mostraba crepitaciones tipo Velcro bilateral.

El laboratorio general mostraba una LDH de $670 \mathrm{UI} / 1$, falla respiratoria hipoxémica grave con una $\mathrm{PaO}_{2}$ de 51,9 mmHg respirando $50 \%$ de oxígeno suplementario; una diferencia alvéoloarterial de $\mathrm{PO}_{2}$ de 49,6 $\mathrm{mmHg}$, recuento de leucocitos de $4.940 / \mathrm{mm}^{3}$, proteína C reactiva de $1 \mathrm{mg} /$ $\mathrm{ml}$ y procalcitonina de $0,05 \mu \mathrm{g} / \mathrm{l}$. Función renal y hepática normales.

La radiografía de tórax de ese momento mostraba un infiltrado difuso bilateral sin derrame pleural ni cardiomegalia y el ecocardiograma mostró solo una leve dilatación de la aurícula izquierda con buena función biventricular.

Se hizo el diagnóstico preliminar de neumonía multilobar de etiología viral, ya que era mediados del mes de junio y, por lo tanto, temporada de Influenza en nuestro país. Se inició tratamiento con oseltamivir, broncodilatadores y a pesar de las guías clínicas en contra, esteroides a dosis de $100 \mathrm{mg}$ de cortisol ev cada $8 \mathrm{~h}$. Subsecuentemente, tanto el panel viral para influenza, parainfluenza y otros virus respiratorios como el examen para VIH fueron negativos.

Una tomografía computarizada de tórax de alta resolución (TACAR) mostraba atenuación en imagen de vidrio deslustrado difusa, bilateral con engrosamiento septal también difuso, patrón conocido como crazy paving, con conservación de los volúmenes pulmonares (Figura 1). La paciente se mantuvo en falla respiratoria y enfrentados a una probable exacerbación de una fibrosis pulmonar idiopática, recibió tres bolos de $1 \mathrm{~g}$ de metilprednisolona seguidos de prednisona en dosis de $1 \mathrm{mg} / \mathrm{kg}$ diario, sin ninguna mejoría luego de 23 días de terapia.

Los exámenes funcionales respiratorios mostraron un patrón restrictivo leve en la espirometría con una CVF de 1,87 1 (69\%) un $\mathrm{VEF}_{1}$ de $1,861(73 \%)$ y una severa limitación al ejercicio, logrando caminar solo $258 \mathrm{~m}$ en $6 \mathrm{~min}(68 \%)$ con desaturación de la hemoglobina a $68 \%$ al final del examen. En esa oportunidad fue imposible realizar un estudio de difusión de monóxido de carbono (DLCO).

Una videobroncoscopía fue normal y en el lavado broncoalveolar no se encontró gérmenes ni células neoplásicas. Ante una paciente grave, que no respondía al tratamiento instaurado, se decidió realizar una biopsia quirúrgica por videotoracoscopía. En la pieza operatoria se demostró mantención de la arquitectura pulmonar con alvéolos llenos de material amorfo eosinófilo que se teñía positivamente con Ácido Peryódico de Schiff (PAS), hallazgos consistentes con el diagnóstico de Proteinosis Alveolar Pulmonar (Figura 2a y b).

El postoperatorio fue tórpido requiriendo de apoyo con ventilación mecánica no invasiva; hizo neumotórax bilateral instalándose drenaje pleural bilateral (Figura 3a) aumento de los parámetros inflamatorios con una imagen de consolidación cavitada en segmento apical del lóbulo inferior izquierdo (Figura 3 a y 3b) por lo que se agregó terapia antibiótica en base a meropenem y vancomicina.

Una vez recuperada del cuadro agudo, la paciente fue sometida a lavado pulmonar total (LPT) bajo anestesia general utilizando $141 \mathrm{de}$ solución fisiológica por cada pulmón de acuerdo al protocolo recomendado por guías internacionales, sin obtener cambios tanto en los parámetros de intercambio gaseoso como en las imágenes y además se observó un agravamiento de sus alteraciones funcionales. En efecto, la TACAR de tórax post LPT fue prácticamente igual a la obtenida al ingreso (Figura 4). Un mes post LPT la paciente

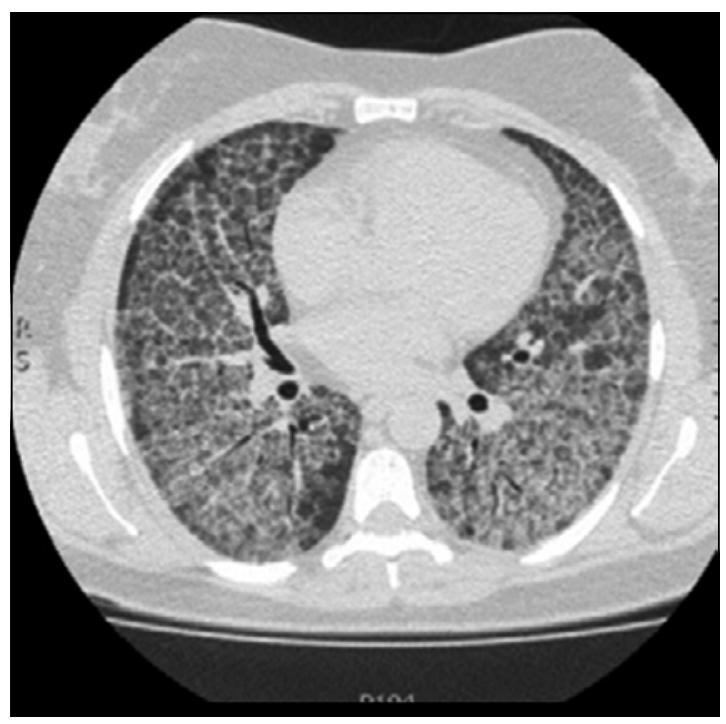

Figura 1. Tomografía computarizada de alta resolución (TACAR) de tórax con patrón crazy paving al ingreso. 

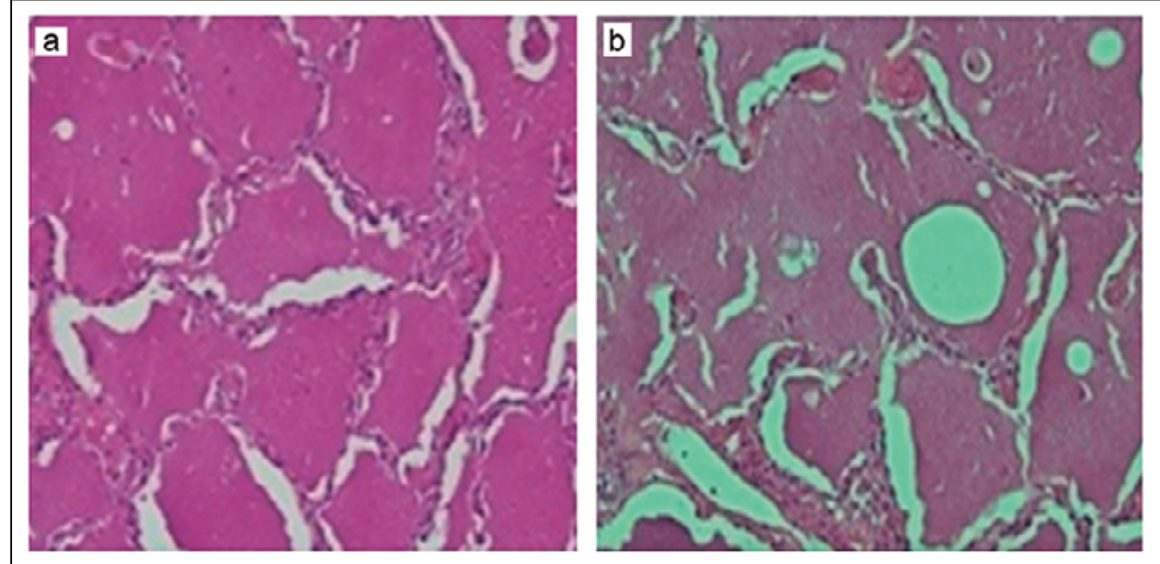

Figura 2. Biopsia pulmonar. a: Alvéolos con material amorfo eosinófilo respetando la arquitectura pulmonar; b: Tinción positiva con PAS.

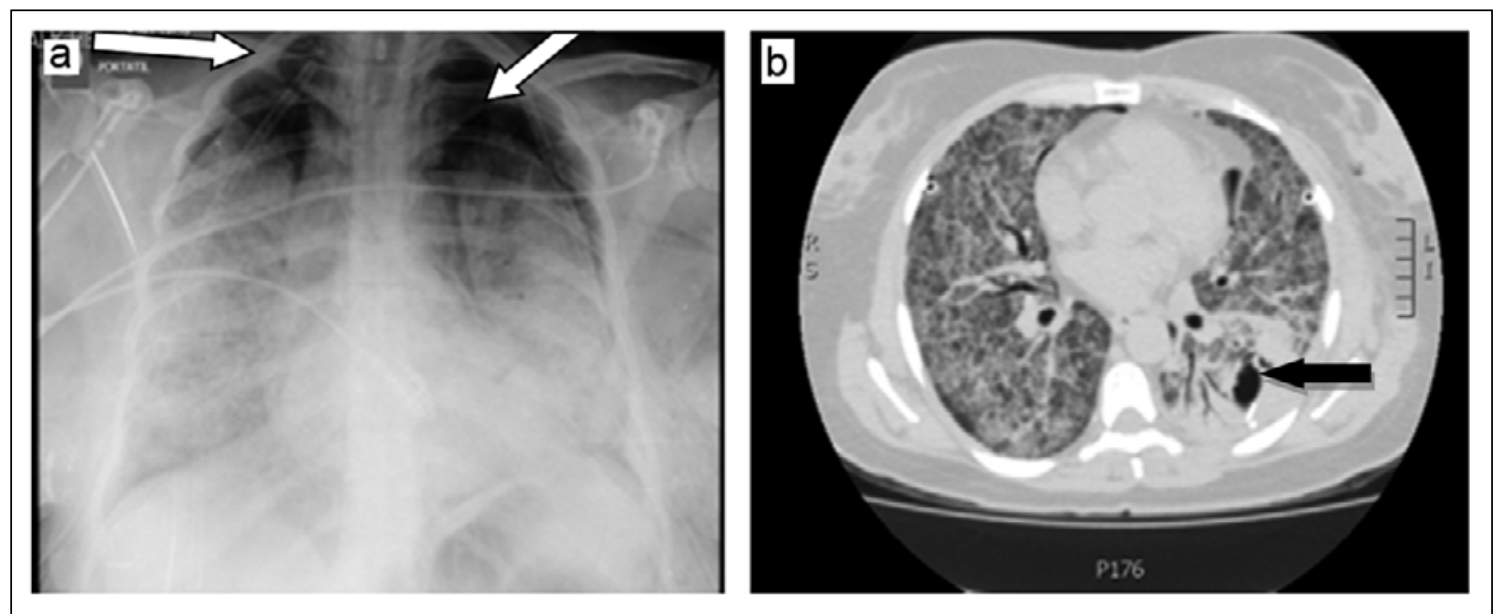

Figura 3. a: Neumotórax bilateral post biopsia pulmonar (flechas blancas). b. Consolidación cavitada en lóbulo inferior izquierdo (flecha negra).

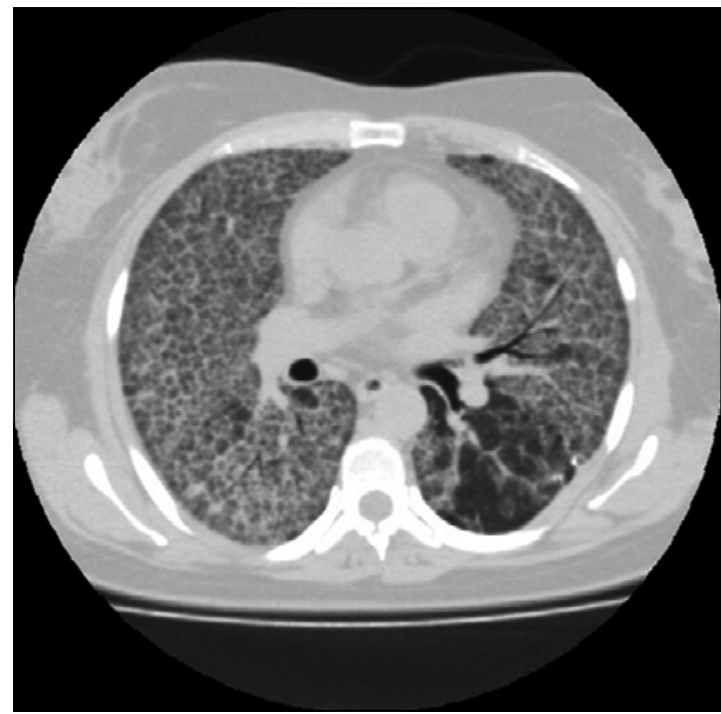

Figura 4. TACAR de tórax post lavado pulmonar total sin cambios con respecto al ingreso. mantenía una $\mathrm{PaO}_{2}$ de 53,3 mmHg con una $\mathrm{FiO}_{2}$ de 50\%; la CVF había disminuido a 1,51 1(50\%), el $\mathrm{VEF}_{1}$ a $1,471(58 \%)$, la DLCO era de $27 \%$ y en el TC6M la distancia recorrida fue de solo $330 \mathrm{~m}$ con una desaturación de la hemoglobina a $64 \%$. Esta situación se mantuvo por varios meses, hecho que le impedía las actividades mínimas de una vida normal dependiendo del uso de $\mathrm{O}_{2}$ suplementario.

En esta paciente, dado el contexto imagenológico el diagnóstico diferencial a considerar era amplio, pero era muy importante descartar una exacerbación aguda de una Fibrosis Pulmonar Idiopática, por la alta morbimortalidad que esta conlleva sobre todo considerando una evolución previa a la hospitalización de un año en una paciente fumadora. Sin embargo, a pesar de ese tiempo, los volúmenes pulmonares se encontraban respetados, el patrón tomográfico era difuso no de predominio subpleural, no había bron- 
quiectasias por tracción, gradiente apico basal ni panalización. No había elementos tampoco para pensar en edema pulmonar cardiogénico, ya que no había historia de cardiopatía un ecocardiograma anodino y las imágenes no mostraban cardiomegalia, ni redistribución circulatoria ni derrame pleural; una neumonía viral en general muestra un infiltrado en parches bilateral y no tan difuso y uniforme como en el caso actual y por lo demás el panel viral fue negativo. No existían elementos de inmunosupresión, no habían quistes ni neumotórax como para considerar una neumonía por Pneumocistis jirovesii y el examen para VIH fue negativo. Por último, frente a un patrón crazy paving, debemos también considerar el diagnóstico de hemorragia alveolar difusa, pero en esta paciente no hubo jamás hemoptisis, anemización progresiva alteraciones en la función renal y la broncoscopía descartó el sangramiento alveolar.

\section{Tratamiento}

Luego del fracaso del LPT y obteniendo el consentimiento informado de la paciente y el acuerdo del Comité de Ética Local de nuestro establecimiento hospitalario que revisa caso a caso las alternativas propuestas para pacientes que requieren de medidas no tradicionales, decidimos recurrir al uso de un producto rara vez utilizado en clínica para lavado pulmonar, pero con fuerte evidencia de sus propiedades físico químicas: excelente transportador de oxígeno, muy baja tensión superficial y muy alto coeficiente de propagación un perfluorocarbono: PFC (Perflubron) con el cual realizamos semanalmente 4 lavados lobares broncoscópicos bajo anestesia local y con $28 \%$ de $\mathrm{O}_{2}$ suplementario en forma ambulatoria. Cada lavado fue realizado impactando el instrumento en el segmento lobar a tratar, instilando a través del canal de trabajo, alícuotas sucesivas de $20 \mathrm{ml}$ de PFC hasta que el líquido aspirado fuese claro. El primer lóbulo en ser lavado fue el lóbulo superior derecho, seguido por el lóbulo medio, división superior izquierda (língula y lóbulo superior izquierdo) y lóbulo inferior izquierdo. Se utilizó un promedio de $250 \mathrm{ml}$ del PFC durante cada procedimiento los que duraron un promedio de $60 \mathrm{~min}$. El efecto de la instilación de PFC se observa en la Figura 5: el tubo de la izquierda muestra el líquido alveolar aspirado luego de la instilación de solución fisiológica. El de la derecha muestra el líquido recuperado inmediatamente luego de la instilación de PFC. Luego de completados los ciclos de lavado, se complementó el tratamiento con 5 sesiones de plasmaféresis con la intención de retirar los posibles anticuerpos circulantes anti factor estimulante de colonias de granulocitos y macrófagos (GM-CSF), cuya titulación no nos fue posible realizar, a objeto de asegurar la ausencia de brotes futuros de la enfermedad. Los resultados fueron sorprendentes y se obtuvieron casi de inmediato. El intercambio gaseoso se normalizó, con una $\mathrm{PaO}_{2}$ de 89,9 $\mathrm{mmHg}$ respirando aire ambiental, la diferencia alvéolo-arterial de $\mathrm{PO}_{2}$ fue de $19 \mathrm{mmHg}$; los índices de función respiratoria mejoraron alcanzando valores cercanos a los normales: $\mathrm{CVF}=2,281$ $(75 \%), \mathrm{VEF}_{1}=1,991(77 \%)$, DLCO aumentó al doble de su valor inicial alcanzando un 55,6\% y en el TC6M la distancia recorrida aumentó a 429 $\mathrm{m}$ sin desaturación de la hemoglobina al finalizar el test. En la TACAR de tórax se evidenció la casi desaparición total de los infiltrados alveolares (Figura 6) y entre los resultados bioquímicos, la LDH disminuyó a 154 IU/1.

Durante el procedimiento de lavado pulmonar con PFC, cada vez que se instiló dicho producto se produjo un aumento importante de la oximetría, la cual descendió al aspirar el producto instilado, pero manteniéndose permanentemente por sobre el valor de la oximetría basal de $92 \%$ (Figura 7), lográndose por otra parte aspirar y retirar fácilmente el líquido proteináceo que inundaba los alvéolos.

La paciente fue dada de alta a su domicilio, asintomática luego de la quinta sesión de plasmaféresis.

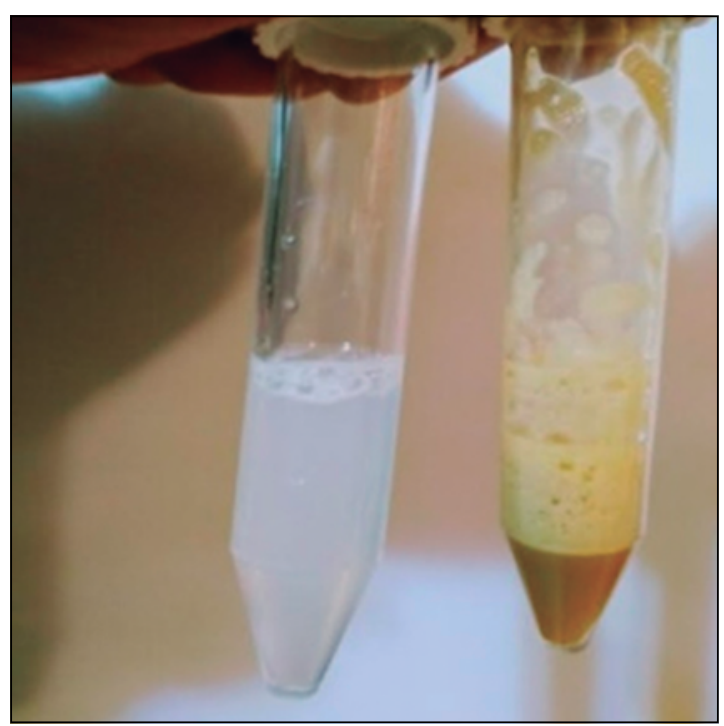

Figura 5. Efecto físico del lavado lobar con perfluorocarbono (PFC). Tubo de la izquierda contiene líquido del lavado con solución salina. Tubo de la derecha contiene líquido del lavado con PFC (observar densidad). 


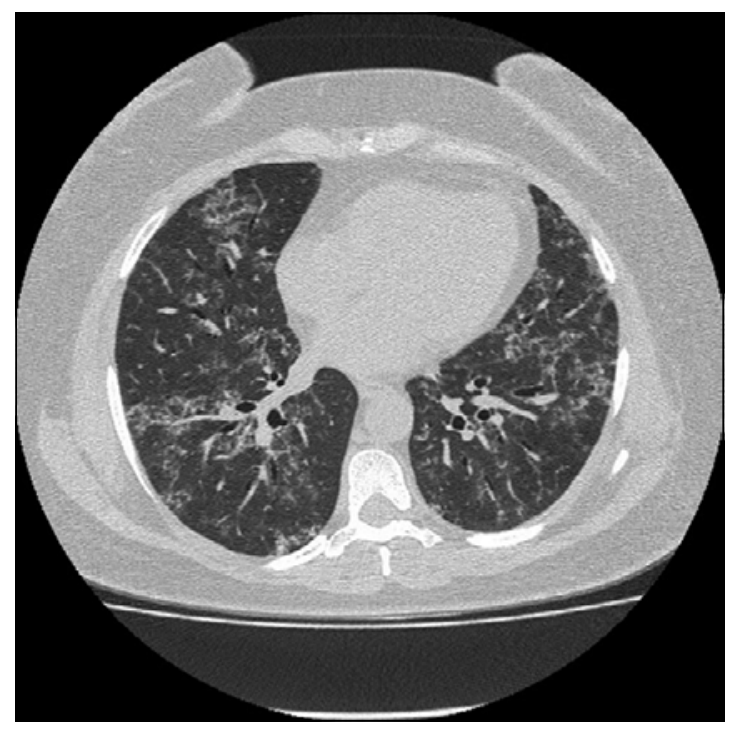

Figura 6. TACAR de tórax luego del lavado con PFC y de la plasmaféresis. Muestra la desaparición casi completa de los infiltrados pulmonares.
Un mes después del alta, retornó a sus labores habituales, sin limitaciones. A los siete meses después de efectuado el procedimiento, se encontraba asintomática, manteniendo una capacidad de ejercicio normal, sin necesidad de medicamentos. La función pulmonar continuó mejorando registrándose una CVF de 2,89 $1(100 \%)$ y un $\mathrm{VEF}_{1}$ de 2,27 1 (92\%) y un TC6M con una distancia recorrida de $465 \mathrm{~m}$ sin desaturación de la hemoglobina. Estos valores se mantienen al año de realizado el lavado con PFC y las sesiones de plasmaféresis.

\section{Discusión}

El patrón crazy paving es un hallazgo tomográfico inespecífico que consiste en un patrón linear formando una red sobrepuesta a una región de atenuación en vidrio deslustrado que se asemeja al pavimento de las calles europeas de la Edad

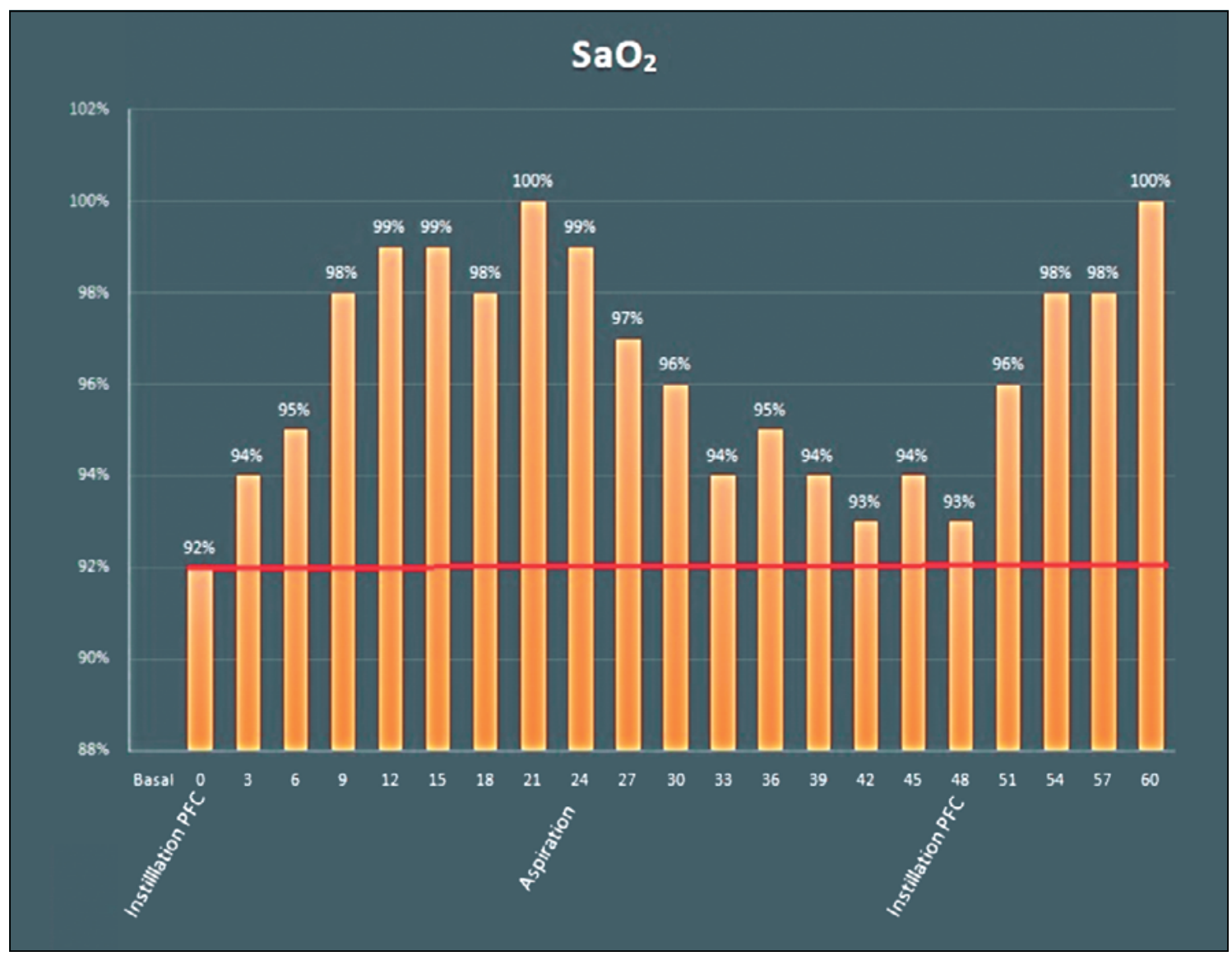

Figura 7. Efecto de la instilación de perfluorocarbono (PFC) para lavado lobar en la oximetría. Los valores porcentuales de la oximetría $\left(\mathrm{SaO}_{2}\right)$ se muestran en el eje vertical. En el eje horizontal se muestra la escala de tiempo en minutos. Las columnas representan la variación de la oximetría durante el lavado con PFC. 
Media. Fue descrito por primera vez en 1989 en una publicación de Murch y Carr que analizaba los hallazgos tomográficos de seis pacientes con PAP y encontraron que tales hallazgos correlacionaban muy bien con el aspecto histológico ${ }^{1}$. El TACAR muestra el engrosamiento de los tabiques inter e intralobulillares responsables por el patrón linear que rodea a los alvéolos pulmonares llenos con líquido, células, sangre o cualquier otro material que opacifique los espacios aéreos o el depósito de material en el borde de los acinos ${ }^{2}$. En los casos descritos por Murch y Carr, el material derivado del surfactante alveolar llenaba los alvéolos causando la imagen de vidrio deslustrado ${ }^{1}$. Al momento de aquella comunicación, este patrón fue considerado como patognomónico de PAP. En la actualidad, aunque aún se le considera como característico de esa condición, ha sido también descrito en muchas otras condiciones agudas o crónicas; así, De Wewer y colaboradores encuentran que la gran mayoría de 59 pacientes con este patrón tomográfico esto es el $45,7 \%$, sufrían de enfermedades infecciosas (bacterianas, virales o fúngicas), seguidas por diferentes Enfermedades Pulmonares Intersticiales Difusas (27,1\%), luego, síndrome de Distress Respiratorio Agudo y Edema Pulmonar Agudo (18,6\%), enfermedades neoplásicas (tumores o linfangitis carcinomatosa $(3,4 \%)$, sarcoidosis $(5 \%)$ y una miscelánea de entidades con un $1,7 \%$ en cada caso entre ellas: PAP, Neumonia Criptogénica en Organización (COP), Neumonia Lipoidea y Enfermedad de huésped versus injerto. En la mayoría de ellas el diagnóstico fue hecho en base a la clínica y la radiología. Solo en un $11,8 \%$ de los casos, fue necesaria la biopsia pulmonar ${ }^{2}$. Existe también una comunicación de un paciente portador de EPOC con una inusual asociación de COP que se presentaba como un patrón crazy paving unilateral ${ }^{3}$. En nuestra paciente, a pesar de un estudio bastante extenso, debimos recurrir a la biopsia pulmonar quirúrgica para obtener el diagnóstico final de PAP.

La PAP es una enfermedad pulmonar huérfana con una prevalencia e incidencia de 3,6/1.000.000 y $0,2 / 1.000 .000$ habitantes respectivamente, que se caracteriza por la acumulación de material lipoproteináceo derivado del surfactante pulmonar, que llena los alvéolos en forma secundaria a la incapacidad de su eliminación por parte de los macrófagos ${ }^{4,5}$. Existen tres formas de PAP: a) una genética, que se ve en el recién nacido y hasta los 9 años de edad, que se asocia a mutaciones recesivas de los genes SFTPB y SFTPC que codifican las proteínas $\mathrm{B}$ y $\mathrm{C}$ del surfactante o en las subunidades receptoras alfa o beta del Factor
Estimulante de Colonias de Granulocitos Macrófagos (GM-CSF) que lo hacen disfuncional ${ }^{6,7}$; b) una PAP secundaria, probablemente originada por la exposición a material tóxico inhalado o a cualquier causa de disminución de la población funcional de macrófagos alveolares (síndromes mielodisplásicos, terapia inmunosupresora) que se ve en individuos menores de 39 años $^{8}$ y c) una PAP autoinmune, la más frecuente de todas, de causa desconocida que se ha sido descrita en pacientes de 56 a 72 años de edad.

Más del $90 \%$ de los pacientes con PAP son adultos que portan auto anticuerpos anti GM$\mathrm{CSF}^{4,9}$. La evolución es hacia las alteraciones del intercambio gaseoso con un amplio espectro de enfermedad que puede ir desde la recuperación espontánea hasta la muerte. La sintomatología es escasa, pero se caracteriza por una disnea de lenta progresión, tos seca e hipoxemia. La radiografía de tórax muestra opacidades bilaterales y la TACAR muestra un patrón crazy paving.

No existe un tratamiento curativo y hasta el momento, la única alternativa aceptada es el 'lavado pulmonar total' con solución salina; procedimiento complejo que involucra un equipo multidisciplinario que incluye a personal de enfermería, fisioterapeutas, anestesiólogos, especialistas en cuidados intensivos y neumólogos el cual debe ser efectuado bajo anestesia general endovenosa, con el paciente ventilado a través de un tubo endotraqueal de doble lumen. El lavado debe ser suplementado por fisioterapia torácica mecánica o manual para remover el acúmulo de material que rellena los alvéolos. Por lo general se ocupa un promedio de 141 de solución salina por cada pulmón a lavar y el procedimiento demora entre 4 a $6 \mathrm{~h}$. Tiene un excelente resultado inmediato, aun cuando algunos pacientes pueden experimentar graves complicaciones, tales como agravamiento de la hipoxemia inicial por alteración severa de la relación ventilación/perfusión por el llenado de un pulmón con líquido, inundación del pulmón contralateral, neumo o hidrotórax, infección por lo general por gérmenes intrahospitalarios y alrededor de un $10 \%$ de los pacientes fracasan a la terapia.

Existen comunicaciones de recurrencia de la enfermedad luego de 4 o 5 años ${ }^{10}$. La indicación del momento en el cual realizar el LPT no es clara, pero de acuerdo a Inoue y colaboradores, nuestra paciente sufría un cuadro severo con algunos de los parámetros de gravedad mencionados por este autor en 2008 como indicación de LPT; la paciente tenía una LDH de $679 \mathrm{UI} / 1$, no se pudo realizar estudio de difusión de $\mathrm{CO}$; la espirometría mostraba una alteración ventila- 
toria restrictiva moderada; tenía una hipoxemia severa con una diferencia de $\mathrm{PO}_{2}$ alvélo-arterial de 49,6 mmHg, acompañados de una limitación muy importante al esfuerzo físico, objetivada por el TC6M durante el cual la desaturación fue significativa.

Alternativas teóricas al LPT son la administración subcutánea o inhalatoria de GM-CSF que podría restaurar el procesamiento macrofágico del material surfactante inactivado, la plasmaféresis, que pretende retirar los auto anticuerpos circulantes o el Rituximab endovenoso, con el objetivo de disminuir la población de células $\mathrm{B}$ productora de estos anticuerpos ${ }^{11-13}$. Una aproximación aún experimental con resultados potencialmente positivos es el trasplante de macrófagos alveolares o de células madre a pacientes que sufren de PAP $^{14}$.

Ante el fracaso del LPT en nuestra paciente, decidimos usar un hidrocarburo flurorinado para repetir el lavado, basándonos en sus propiedades físicas y químicas: la unión química CarbonoFlúor es extremadamente estable lo que hace que el compuesto obtenido sea química y metabólicamente inerte. Su capacidad de transportar $\mathrm{O}_{2}$ es tres veces la de la sangre y lo hace por vía de la solubilidad directa tal como en el plasma; tiene un muy baja tensión superficial; dos veces la densidad del agua y un coeficiente de propagación muy elevado lo que permite su distribución en las zonas dependientes del pulmón, teóricamente manteniendo abiertos los alvéolos sanos, reclutando los alvéolos colapsados o desplazando el material lipoproteináceo que los llena hacia las vías aéreas desde donde puede ser fácilmente aspirado y eliminado. Por otro lado, hay resultados de investigaciones que ha sugerido un efecto antiinflamatorio de los $\mathrm{PFC}^{15-17}$.

En vista de los resultados obtenidos, creemos que tanto las propiedades físicas como químicas de los PFC quedaron demostradas con su utilización en esta paciente ya que durante el procedimiento de lavado, la oximetría se mantuvo permanentemente sobre la línea basal (Figura 7) y el líquido proteináceo fue fácilmente extraído desde las vías aéreas (Figura 6). Al mismo tiempo, podríamos especular que su efecto antiinflamatorio fue causante de la normalización de la LDH observada. El procedimiento fue efectuado sin complicaciones en forma ambulatoria tomando un promedio de 60 min por cada lavado lobar, evitando la necesidad de hospitalización, largos períodos de anestesia general, ventilación mecánica y las eventuales complicaciones del LPT en una paciente seriamente enferma. En un intento de ofrecer el máximo de éxito con las posibilida- des terapéuticas que en nuestra paciente aplicamos, con la intención de retirar de la circulación los probables anticuerpos anti GM-CSF cuya titulación no nos fue posible realizar, agregamos a los lavados con Perflubrón, 5 sesiones de plasmaféresis, basándonos en el protocolo descrito en 2015 por Garber y colaboradores quienes trataron a un paciente refractario al lavado pulmonar total, usando GM-CSF exógeno y rituximab con 5 sesiones de plasmaféresis en días consecutivos, seguidos de nueva administración de rituximab obteniendo una muy significativa disminución del título de anticuerpos anti GM-CSF, junto con la mejoría clínica y funcional del enfermo ${ }^{18}$. Pensamos que aunque no tuvimos oportunidad de marcar anticuerpos anti GM-CSF en el líquido de lavado alveolar, nuestro enfoque al considerar el cuadro como una PAP autoinmune fue correcto ya que se descartó cualquier tipo de neoplasia especialmente hematológica y la paciente evolucionó progresivamente hacia el agravamiento sintomático y funcional, sin cambios en las imágenes del TACAR luego del primer lavado pulmonar total efectuado según los protocolos habituales y estando alejada por largo tiempo de un factor tóxico probable en su actividad laboral y que por lo tanto, la forma de enfrentamiento final del caso fue la adecuada.

\section{Conclusiones}

La proteinosis alveolar pulmonar es un cuadro muy poco frecuente lo que hace que al enfrentarlo no se piense en él.

El patrón tomográfico crazy paving puede sugerir el diagnóstico.

El caso presentado correspondería al 10\% de pacientes en que se ha encontrado que fracasa la terapia de elección que es el lavado pulmonar total.

En este caso el uso de Perfluorocarbono resultó ser una alternativa válida y segura al lavado pulmonar total tradicional.

\section{Bibliografía}

1.- MURCH CR, CARR DH. Computed tomography appearances of pulmonary alveolar proteinosis. Clin Radiol 1989; 40: 240-3.

2.- DE WEWER W, MEERSSCHAERT J, COOLEN J, VERBEKEN E, VERSCHAKELEN JA. The crazy-paving pattern: a radiological-pathological correlation. Insights Imaging 2011; 2: 117-32 DOI 10.1007/s13244010-0060-5. 
3.- KUNAL S, PILANIYA V, JAIN S, SHAH A. Crazy-paving' pattern: an exceptional presentation of cryptogenic organising pneumonia associated with chronic obstructive pulmonary disease. BMJ Case Rep Published online: 19 April 2016 doi 10.1136/bcr-2016215445.

4.- BONELLA F, THEEGARTEN D, GUZMÁN J, COSTABEL U. Alveolar lipoproteinosis syndromes in: Orphan Lung Diseases. European Respiratory Society 2011 printed by Latimer Trend \& Co. Ltd. Plymouth UK. Edited by J-F Cordier. Editor in Chief T Welte. Chapter 10.

5.- CARRINGTON JM, HERSHBERGER DM. Pulmonary Alveolar Proteinosis (Updated 2018 March 20) Stat Pearls (Internet) Treasure Island (FL) StatPearls publishing Disponible en: https//www.nlm.bov/books/ NBK482308.

6.- SUZUKI T, SAKAGAMI T, YOUNG LR, CAREY BC, WOOD RE, LUISETTI M, et al. Hereditary Pulmonary Alveolar Proteinosis: pathogenesis, presentation, diagnosis and therapy. Am J Respir Crit Care Med 2010; 182: 1292-304.

7.- $\quad$ BORIE R, DANEL MP, DEBRAY C. Pulmonary Alveolar Proteinosis. Eur Respir J 2011; 120: 98-107.

8.- ISHII H, TAZAWA R, KANEKO C, SARAYA T, INOUE Y, HERMANO E, et al. Clinical features of secondary Pulmonary Alveolar Proteinosis: Pre mortem cases in Japan. Eur Respir J 2011; 37: 465-8. doi: 10.1183/09031936.00092910.

9.- INOUE Y, TRAPNELL BC, TAZAWA R, ARAL T, TAKADA T, HIZAWA N, et al Characteristics of a large cohort of autoimmune Pulmonary Alveolar Proteinosis patients. Am J RespirCrit Care Med 2008; 177: 752-62

10.- CAMPO I, LUISETTI M, GRIESE M, TRAPNELL BC; BONELLA F, GRUTTERS J, et al. Whole lung lavage for pulmonary alveolar proteinosis: A global survey for current practices and procedures. Orphanet J Rare Dis 2016; 11: 115. doi: 101186/s13023-016-0497-9.

11.- TAZAWA R, TRAPNELL BC, INOUE Y, ARAI T, TAKADA T, NASUHARA Y, et al. Inhaled granulocyte-macrophage colony stimulating factor as therapy for Pulmonary Alveolar Proteinosis. Am J Respir Crit Care Med 2010; 181: 1345-54.

12.- LUISETTI M, PEROTTI C, CAMPO I, MARIANO F,POZZI E, TRAPNELL BC, et al. Plasmapheresis for treatment of Pulmonary Alveolar Proteinosis. Eur Respir J 2009; 33: 1220-2.

13.- KAVURU MS, MALU A, MARSHALL I BAMA BP, MEZIANE M, HUIZAR I, et al. An open label trial of rituximab therapy in Pulmonary Alveolar Proteinosis. Eur Respir J 2011; 38: 1361-7.

14.- DOERSCHUK CM. Pulmonary alveolar proteinosis and macrophage transplantation. N Engl J Med 2015;372:1762-4. doi: 10.1056/NEJMcibr1413035.

15.- PATANKA, NIKHIL AL-IBRAHIM O. Use of perflubron for pulmonary lavage in severe pediatrics ARDS. Crit Care Med 2015; 43: 180 doi: 10.1097/01. ccm.000047454.

16.- CROCE MA, FABIAN TC, PATTON JH Jr, MELTON SM, MOORE M, TREMTHEM LL. Partial liquid ventilation decrases the inflamatory response in the alveolar environment of trauma patients. J Trauma 1998; 45: 273-80.

17.- WOODS C, NESLUND G, KORNBRUST E, FLAIM SF. Perflubron attenuates neutrophil adhesion to activated endothelial cells in vitro. Am J Physiol Lung Cell Mol Physiol 2000; 278: L1008-17.

18.- GARBER B, ALBORES J, WANG T, NEVILLE TH. A plasmapheresis protocol for refractory Pulmonary Alveolar Proteinosis. Lung 2015; 193: 209-11. doi: 10.1007/s00408-014-9678-2.

Correspondencia a:

Dr. Patricio Rioseco S.

Alto Horno 777, Talcahuano, Chile.

Email: pariosecomail.com 